\title{
Conformidade dos softwares de controle patrimonial aos preceitos do CPC 27 e ICPC 10
}

\section{The conformity of asset control software to the principles of CPC 27 and ICPC 10}

Prof. Dr. Paulo Roberto da Cunha (FURB - SC/Brasil) - pauloccsa@furb.br - R. Antônio da Veiga, 140, Sala D 202, Bairro Victor Konder, 89012-900, Blumenau/SC, fone: (55) 47-3321-0565

Soraia Pamplona (FURB - SC/Brasil) - soraia.pamplona@terra.com.br

Profa. Dra. Ilse Maria Beuren (UFPR - PR/Brasil) - ilse.beuren@gmail.com

Prof. Dr. Roberto Carlos Klann (FURB - SC/Brasil) - rklann@furb.br

RESUMO A convergência da contabilidade brasileira às normas internacionais passou a exigir também a adequação de softwares contábeis às novas regras estabelecidas. Em 2009, a Deliberação CVM no 583 e a Resolução CFC no 1.177 tornaram obrigatória a aplicação do Pronunciamento Técnico 27 do Comitê de Procedimentos Contábeis, que dispõe sobre o Ativo Imobilizado. Este estudo objetiva verificar se os softwares de controle patrimonial atendem aos preceitos do CPC 27 e da ICPC 10. Pesquisa qualitativa descritiva foi realizada por meio de um estudo multicaso. Um roteiro de entrevista, com os itens abordados no CPC 27 e na ICPC 10, foi aplicado aos desenvolvedores de softwares de controle patrimonial de três empresas de softwares da região sul do Brasil. Os resultados da pesquisa mostram que a média geral das três empresas analisadas foi de $86 \%$ de atendimento aos tópicos abordados nesta pesquisa. Conclui-se que, de modo geral, os softwares de controle patrimonial atendem aos preceitos do CPC 27 e da ICPC 10, com exceção dos conceitos de impairment e deemed cost que não foram contemplados.

Palavras-chave CPC 27. ICPC 10. Ativo Imobilizado. Software. Controle Patrimonial.

ABSTRACT The convergence of Brazilian accounting to international standards also requires adjusting accounting software to the new rules. In 2009, SEC Resolution No. 583 and CFC Resolution No. 1177 made it mandatory toapply Pronouncement 27 of the Accounting Procedures Committee, concerning Fixed Assets. The goal of this study is to verify whether the asset control software meets the requirements of CPC 27 and ICPC 10. A descriptive, qualitative study was carried out using a multi case study. An interview guide, with the items discussed in CPC 27 and ICPC 10, was applied to the software developers to control assets of three software companies in southern Brazil. The survey results show that the overall average of the three companies examined was $86 \%$ of compliance to the topics covered in this research. It was concluded that, in general, asset control software meets the precepts of CPC 27 and ICPC10, except for impairment and deemed cost concepts, which were not covered.

Keywords CPC 27. ICPC 10. Fixed Assets. Software. Asset Control. 


\section{INTRODUÇÃO}

A globalização dos mercados passou a exigir a harmonização das demonstrações contábeis no sentido de auxiliar investidores, gestores e analistas financeiros de todo o mundo a utilizar dados comparáveis do patrimônio e dos resultados das empresas. No Brasil também há essa preocupação, com projetos sendo implementados nessa direção. Cita-se a criação do Comitê de Pronunciamentos Contábeis (CPC), com a finalidade de estudar, preparar e emitir pronunciamentos técnicos sobre procedimentos contábeis e uniformizar os processos relacionados à convergência da contabilidade brasileira aos padrões internacionais.

Outros fatos ocorreram para promover a convergência às normas internacionais. Dentre eles, a emissão do Comunicado no ${ }^{\circ}$ 14.259/06 pelo Banco Central, que prevê a identificação das necessidades da convergência, em consonância com o International Accounting Standards Boards (IASB) e a International Federation Accountants (IFAC), e assim adotar as normas do International Financial Reporting Standards (IFRS) nas publicações das demonstrações financeiras desde 2010.

Órgãos como o Comitê de Pronunciamentos Contábeis (CPC), o Conselho Federal de Contabilidade (CFC) e a Comissão de Valores Mobiliários (CVM) - órgão regulador do mercado de capitais brasileiro com a atribuição de instituir e fiscalizar a aplicação das normas contábeis pelas companhias de capital aberto - passaram a atuar na normatização contábil. Em 2007, a Lei no 11.638/07 (BRASIL, 2007), que alterou a Lei n 6.404/76, Lei das Sociedades por Ações, delegou aos respectivos órgãos a responsabilidade da regulação das normas de contabilidade.

Neste estudo interessa em específico o Pronunciamento Técnico CPC 27, do Ativo Imobilizado, que foi aprovado e teve sua aplicação tornada obrigatória pela Deliberação da CVM no 583/09 e a Resolução do CFC no 1.177/09. Esse Pronunciamento teve por base a International Accounting Standards 16 (IAS 16) e objetiva estabelecer o tratamento contábil para ativos imobilizados, bem como a divulgação de informações que permitam o entendimento e a análise desse grupo de contas.

Prevendo dificuldades na operacionalização na íntegra do Pronunciamento Técnico CPC 27 pelas empresas, o Comitê de Pronunciamentos Contábeis preparou uma Interpretação Técnica para aplicação inicial e, em 2009, a Deliberação CVM n ${ }^{\circ}$ 619/09 e a Resolução CFC no 1.263/09 aprovaram e tornaram obrigatória a aplicação da Interpretação Técnica 10 (ICPC 10), que aborda a interpretação sobre a aplicação inicial ao ativo imobilizado e a propriedade para investimento, conforme os pronunciamentos técnicos CPCs 27, 28, 37 e 43.

Este movimento precisa ser acompanhado com mudanças nos softwares de controle patrimonial. As dificuldades que os profissionais da área contábil e os desenvolvedores de softwares de contabilidade vêm encontrando na sua implementação, sugere a existência de uma lacuna de pesquisa. Considera-se oportuno investigar em que medida a atualização dos softwares de controle patrimonial levou em conta as mudanças na normatização contábil trazida pelo CPC 27, Ativo Imobilizado, e da ICPC 10. 
Diante desse contexto, elaborou-se a seguinte questão de pesquisa: Em que medida os softwares de controle patrimonial desenvolvidos em empresas brasileiras de softwares estão atendendo aos preceitos do CPC 27 e da ICPC 10? Assim, o objetivo do estudo é verificar em que medida os softwares de controle patrimonial estão atendendo aos preceitos do CPC 27 e da ICPC 10. A relevância da pesquisa está em verificar se os softwares de controle patrimonial estão adequados às mudanças contábeis estabelecidas no CPC 27 e na ICPC 10.

Com o processo de convergência das normas locais brasileiras para as normas internacionais de contabilidade busca-se conferir maior qualidade às informações contábeis, de modo que o tomador de decisões possa realizar análises comparativas de empresas de diferentes países em âmbito mundial. Macedo et al. (2013, p. 73) destacam que existem alguns estudos que procuram verificar se a adoção do padrão International Financial Reporting Standards (IFRS) traz mudanças significativas no conteúdo informacional das demonstrações financeiras.

Martins e Paulo (2010) aduzem que a literatura indica que a adoção das IFRS influencia e se reflete nas demonstrações financeiras das organizações, mas poucos estudos utilizam evidências empíricas para descrever o reflexo dessa adoção sobre os indicadores de desempenho das companhias. Por conseguinte, investigaram o reflexo da adoção das IFRS sobre os indicadores de desempenho das companhias abertas brasileiras.

Raupp e Beuren (2009) analisaram o processo de mensuração do valor econômico de ativos imobilizados tendo por base a integração do fair value e do impairment test. Carvalho et al. (2012) analisaram o processo de reconhecimento e mensuração do ativo imobilizado face aos padrões internacionais de contabilidade no âmbito do setor público brasileiro, realizando um estudo de caso na empresa Anatel.

No entanto, o processo de convergência das normas contábeis brasileiras às normas internacionais de contabilidade implica também mudanças nos softwares contábeis. Assim, este estudo diferencia-se ao investigar em que medida houve a atualização dos softwares de controle patrimonial em vista às mudanças ocorridas com a aprovação do CPC 27, Ativo Imobilizado, e da ICPC 10, para subsidiar as empresas abrangidas por essa normatização.

Para atingir o objetivo do estudo realizou-se um comparativo do disposto no Pronunciamento Técnico CPC 27 e na Interpretação Técnica ICPC 10, do Comitê de Pronunciamentos Contábeis, com as características inerentes em softwares de controle patrimonial de três empresas de softwares da Região Sul do Brasil. As empresas escolhidas são consideradas referências na implementação do módulo patrimonial nos sistemas Enterprise Resource Planning (ERP) na região sul do Brasil.

O estudo está organizado em cinco seções, iniciando com esta introdução. Na seção 2 é apresentada a revisão bibliográfica relativa ao ativo imobilizado, com ênfase no seu reconhecimento, no impairment test, na depreciação e na adoção inicial do CPC 27. A seção 3 apresenta o método e os procedimentos de pesquisa adotados. A seção 4 contempla o estudo multicasos, em que são cotejados os itens preconizados no CPC 27 e no ICPC 10 com estas propriedades no módulo patrimonial dos três softwares objeto do estudo multicasos. A seção 5 trata das considerações finais do estudo realizado. 


\section{REVISÃO BIBLIOGRÁFICA}

O ativo imobilizado é constituído de bens e direitos que tem por natureza a manutenção e conservação das atividades da empresa. Refere-se aos bens fixos adquiridos ou produzidos pela empresa, não destinados para venda ou transformação no seu processo produtivo. No ativo imobilizado são classificados os itens tangíveis, ou seja, os que são utilizados nas operações normais da empresa, com vida útil prolongada por mais de um exercício social e que possuem um corpo físico (IUDÍCIBUS, 2004).

Iudícibus (2004, p. 201) afirma que "sua característica principal é a de ser utilizado nas operações normais da empresa e sua vida estende-se, usualmente, além de qualquer período menor que o do ciclo de capacidade". O autor cita como exemplos, terrenos, edifícios, equipamentos, instrumentos e ferramentas, móveis e utensílios, moldes e veículos. Incluem-se as operações de arrendamento mercantil, que apesar de não pertencerem legalmente à empresa, seus riscos, benefícios e controle serão de responsabilidade do arrendatário, assim como os benefícios futuros gerados por este bem serão usufruídos por ele.

O IASB, no IAS 16, define que os itens de propriedade, plantas e equipamentos devem ser reconhecidos como ativos, quando: a) é provável que futuros benefícios econômicos associados aos ativos fluirão para a entidade; e b) o custo do ativo possa ser mensurado com confiabilidade (IASPLUS, 2003).

A convergência da contabilidade brasileira às normas internacionais resultou em diversas alterações no reconhecimento dos elementos patrimoniais e de resultados das empresas. Neste estudo, o foco de análise são as mudanças propostas no CPC 27, relacionadas ao tratamento contábil do imobilizado, e suas implicações nos softwares de controle patrimonial. Assim, na seqüência discorre-se sobre o reconhecimento dos ativos imobilizados, o impairment, a depreciação e a adoção inicial dos preceitos do CPC 27.

\subsection{Reconhecimento dos ativos imobilizados}

O CPC 27 define custo do ativo imobilizado como "o montante de caixa ou equivalente de caixa pago ou o valor justo de qualquer outro recurso dado para adquirir um ativo na data da sua aquisição ou construção" (CPC, 2009). O CPC 27 ainda estabelece que o custo de um item do ativo imobilizado compreende:

a) seu preço de aquisição, acrescido de impostos de importação e impostos não recuperáveis sobre a compra, depois de deduzidos os descontos comerciais e abatimentos;

b) quaisquer custos diretamente atribuíveis para colocar o ativo no local e condição necessários para o mesmo ser capaz de funcionar da forma pretendida pela administração;

c) a estimativa inicial dos custos de desmontagem e remoção do item e de restauração do local (sítio) no qual este está localizado. Tais custos representam a obrigação em que a entidade incorre quando o item é adquirido ou como consequência de usá-lo durante determinado período para finalidades diferentes da produção de estoque durante esse período. 
O CPC 27, no item 8, considera custo de aquisição, além do preço devido ou pago pelo bem, todos os demais gastos incorridos pela entidade e necessários para colocar este bem em uso. Sobressalentes, peças de reposição, ferramentas e equipamentos de uso interno também são classificados como ativo imobilizado quando a entidade espera usá-los por mais de um exercício social (CPC, 2009). Esse entendimento já era exposto por Iudícibus (2004, p. 202), que "o custo inicial do bem precisa incluir: fretes, taxas alfandegárias quando aplicável, outras taxas e impostos não recuperáveis, custo de manuseio e estocagem, custos de instalação na base física de operação".

O Pronunciamento Técnico CPC 27 destaca que é necessário exercer julgamento ao aplicar os critérios de reconhecimento às circunstâncias específicas da entidade e salienta que é apropriado agregar itens individualmente insignificantes, tais como, moldes, ferramentas e bases, e aplicar os critérios ao valor do conjunto (CPC, 2009). A entidade deve avaliar, segundo o princípio de reconhecimento, todos os seus custos de ativos imobilizados no momento em que eles são incorridos. Esses custos incluem os incorridos inicialmente para adquirir ou construir um item do Ativo Imobilizado e os incorridos posteriormente para renová-lo, substituir suas partes, ou prover sua manutenção.

No caso de ativos construídos pela entidade, o CPC 27 institui, no seu item 22, que o custo do ativo será determinado nos mesmos moldes dos ativos adquiridos e que valores anormais de materiais, mão de obra ou outros recursos desperdiçados na construção não integram o valor contábil do bem. O CPC 27 destaca ainda que o custo deve ser reconhecido no ativo imobilizado quando for provável que futuros benefícios econômicos associados ao item fluirão para a entidade e o custo do item puder ser mensurado confiavelmente (CPC, 2009).

Despesas com juros decorrentes de compras a prazo também não integram o valor do item e devem ser reconhecidas como despesa, a não ser que este item seja construído pela própria empresa. Estes critérios são estabelecidos pelo CPC 20, Custos de Empréstimos, que descreve os juros diretamente atribuíveis à construção como aqueles que seriam evitados se os gastos com o ativo qualificável não tivessem sido feitos, quando for provável que eles resultarão em benefícios econômicos futuros para a entidade e que tais custos possam ser mensurados com segurança (CPC, 2011).

\subsection{Impairment}

A realização do impairment test tem por finalidade "verificar a recuperabilidade do valor econômico dos ativos, ou seja, confirmar se o retorno econômico dos ativos está coerente com os valores registrados contabilmente" (SILVA et al., 2009). Desse modo, "se for constatado que o ativo possui um valor superior aos benefícios que ele pode proporcionar, significa que existe uma perda embutida, e esta deverá ser reconhecida no resultado da empresa" (SOUZA et al., 2011, p. 69).

As normas contábeis sobre impairment em âmbito internacional foram definidas pelo International Accounting Standards Board (IASB), no IAS 36 - Impairment of Assets (IASB, 2004). Ainda se destacam duas normas norte-americanas do Financial Accounting Standards Board (FASB), o SFAS 142 - Goodwill and Other Intangible Assets (FASB, 2001a) e o SFAS 144 - Accounting for the Impairment or Disposal of Long-Lived Assets (FASB, 2001b). No Brasil, o Comitê de Pronunciamentos Contábeis (CPC) emitiu em 17 de setembro de 2007 o Pronunciamento Técnico CPC 01 - Redução ao Valor Recuperável de Ativos (SILVA et al., 2009). 
Ao comentar o SFAS $n^{\circ}$ 144, Reinstein e Lander (2004) enumeram alguns indicadores da existência de impairment:

a) decréscimos no preço de mercado do ativo ou do grupo de ativos;

b) mudanças na extensão e na maneira que os ativos serão utilizados;

c) mudanças físicas no ativo;

d) mudanças adversas em fatores legais ou no clima dos negócios que podem afetar o valor do ativo ou uma ação ou avaliação adversa do regulador;

e) acumulação de custo excedente ao montante originalmente esperado para aquisição ou construção do ativo;

f) perdas operacionais ou no fluxo de caixa do período corrente, combinadas com um histórico de perdas operacionais ou de fluxo de caixa, ou uma projeção ou estimativa que demonstrem perdas continuadas associadas com o ativo; $\mathrm{e}$

g) é provável que a firma não disponha desse ativo antes do fim de sua vida útil remanescente previamente estimada.

No Brasil, o CPC 01 determina que a perda por impairment seja reconhecida quando o valor contábil do ativo em uso for superior ao seu valor recuperado na projeção de geração de caixa ou do valor de realização para os ativos em descontinuidade. Estabelece ainda a obrigatoriedade da redução ao valor recuperável, conhecido como teste de recuperabilidade, aos ativos descontinuados, ativos disponíveis para a venda e ativos em uso (CPC, 2007).

Para os ativos em uso deve-se apurar o seu valor econômico, ou seja, registrar a perda quando o valor contábil do ativo for superior ao seu valor em uso, valor este, indicado pelo valor presente de fluxos de caixa futuros estimados, resultante do uso de um ativo ou de uma unidade geradora de caixa (CPC, 2007).

De acordo com o item 30 do CPC 27, é obrigatório o reconhecimento da perda apontada pelo teste de recuperabilidade a todos os ativos imobilizados (CPC, 2009). O CPC 01 destaca que a entidade deve avaliar ao fim de cada exercício social, se há indicação de que um ativo possa ter sofrido desvalorização, se sim, deve ser feito o reconhecimento da perda em conta redutora específica do ativo (CPC, 2007).

O CPC 01 estabelece ainda que, ao final de cada exercício a entidade deve divulgar a aplicação do impairment, destacando: o valor da perda ou reversão de perda com desvalorizações reconhecidas no período, e eventuais reflexos em reservas de reavaliações; os eventos e circunstâncias que levaram ao reconhecimento ou reversão da desvalorização; relação dos itens que compõem a unidade geradora de caixa e uma descrição das razões que justifiquem a maneira como foi identificada a unidade geradora de caixa; e se o valor recuperável é líquido de venda deve ser divulgada a base usada para determinar esse valor, mas se o valor recuperável é do ativo em uso, deve ser divulgada a taxa de desconto usada nessa estimativa (CPC, 2007).

\subsection{Depreciação}

A depreciação, segundo Law (2004, p. 242 apud BAUM; DEVANEY, 2008, p. 197), pode ser definida como "a taxa de declínio no valor do aluguel (capital) de um ativo (ou grupo de ativos) ao longo do tempo relativo a um ativo (ou grupo de ativos) avaliado como novo com especificação contemporânea”. Baum e Devaney (2008) afirmam que essa definição está relacionada ao conceito de depreciação econômica de ativos. Ela é diferente da depreciação utilizada na contabilidade corporativa, que está fundamentada na redução do valor contábil de ativos ao longo do tempo para refletir, no resultado das companhias, o consumo de ativos de capital que precisam ser repostos no futuro. 
A definição de depreciação, segundo o CPC 27, "é a alocação sistemática do valor depreciável de um ativo ao longo de sua vida útil" (CPC, 2009). A Lei no 6.404/76 (BRASIL, 1976), alterada pela Lei $\mathrm{n}^{\circ} 11.941 / 09$, em seu art. $183, \S 2^{\circ}$, estabelece que a redução do valor do ativo imobilizado deve ser registrada periodicamente nas respectivas contas, a saber: "a) depreciação, quando corresponder à perda do valor dos direitos que têm por objeto bens físicos sujeitos a desgaste ou perda de utilidade por uso, ação da natureza ou obsolescência".

Segundo Santos e Schmidt (2002), a depreciação a ser contabilizada de acordo com a Lei das Sociedades por Ações, é o valor que corresponder ao desgaste efetivo pelo uso ou perda de utilidade dos bens físicos, inclusive por ação da natureza ou obsolescência. $O$ valor do bem a ser depreciado é a diferença entre o custo desse bem e o seu valor residual, dividido pelo prazo de sua vida útil. A despesa de depreciação deve ser apropriada sistematicamente no resultado, a menos que seja incluída no valor contábil de outro ativo, como o de atividades de desenvolvimento em que a depreciação pode ser incluída no custo do ativo intangível.

O CPC 27, no item 6, estabelece que o valor residual e a vida útil de um ativo devem ser revisados pelo menos ao final de cada exercício. A vida útil do bem "é o período de tempo durante o qual se espera utilizar o ativo, ou o número de unidades de produção que a entidade espera obter pela utilização do ativo" (CPC, 2009). Portanto, a vida útil de um ativo é definida em função da utilidade esperada desse ativo para a entidade. Segundo o CPC 27, os seguintes fatores são considerados na determinação da vida útil:

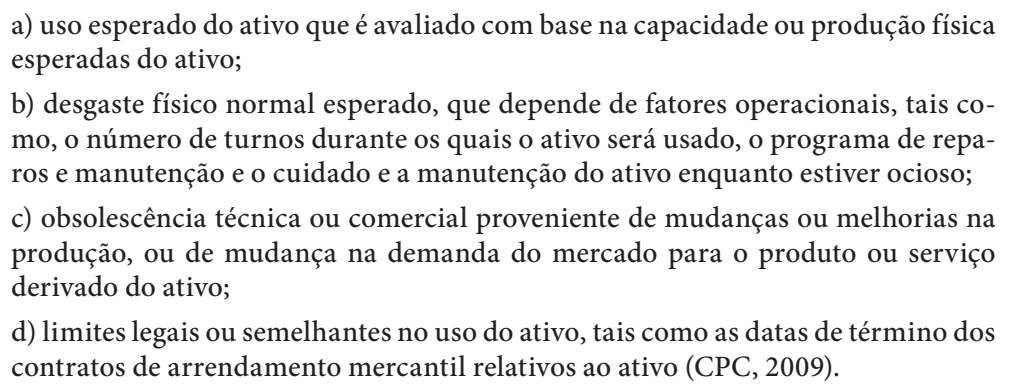

As dificuldades associadas à definição da vida útil do bem estão relacionadas, "além das causas físicas do desgaste pelo uso e pela ação de elementos da natureza, a fatores funcionais, tais como a inadequação e o obsoletismo, resultantes do surgimento de substitutos mais aperfeiçoados" (IUDÍCIBUS; MARTINS, 2007, p. 223).

Quanto aos componentes de valor significativo, conforme itens 43 a 45 do CPC 27, é considerado que um componente de custo significativo em relação ao valor total de um item do ativo imobilizado deve ser depreciado separadamente. Se mais de um componente significativo tiver vida útil e método de depreciação similar, estes componentes podem ser agrupados no cálculo da depreciação.

Da mesma forma, o remanescente dos itens do ativo imobilizado, aqueles componentes que não são individualmente significativos, são depreciados separadamente. As manutenções preventivas nos itens do ativo imobilizado não evitam a necessidade de depreciá-lo. Segundo o item 55 do CPC 27, "a depreciação do ativo se inicia quando este está disponível para uso [...]. A depreciação de um ativo deve cessar na data em que o ativo é classificado como mantido para venda" (CPC, 2009).

Nesse contexto, o CPC 27 estabelece que a depreciação não cessa quando o ativo se torna ocioso ou é retirado do uso normal. No entanto, de acordo com o método de depreciação pelo uso, o valor da depreciação pode ser zero quando não houver produção (CPC, 2009). 


\subsection{Ad oção inicial dos preceitos do CPC 27}

Em virtude das mudanças das práticas contábeis advindas da convergência das normas brasileiras às Normas Internacionais de Contabilidade, na adoção inicial do CPC 27, são necessários ajustes ao valor justo nos saldos iniciais das demonstrações contábeis. Esses ajustes são regidos pelo conceito de custo atribuído (deemed cost), que estão previstos no CPC 37 (CPC, 2010) e no CPC 43 (CPC, 2010). No entanto, a ICPC 10 traz alguns esclarecimentos sobre a aplicação da adoção inicial no que concerne ao ativo imobilizado (CPC, 2009).

No item 39 do CPC 02 - Esclarecimentos sobre Demonstrações Contábeis 2008, é recomendada a aplicação do CPC 27 no ano de 2010, permitindo que em 2008 as empresas utilizassem as taxas que já vinham adotando, mas, quando da adoção das normas em 2010, os efeitos de 2009 devessem ser calculados para fins comparativos.

Neste caso, a vida útil e o valor residual dos bens, que devem ter seus valores revisados a cada exercício, e conforme estabelece o CPC 27 (CPC, 2009), têm seus ajustes iniciais aplicados a partir de $1^{\circ}$ de janeiro de 2010. Para o CPC 37 (CPC, 2010), esses ajustes podem ser decorrentes de significativas variações de preços desde a aquisição do ativo, e provocar distorções no balanço patrimonial e no resultado.

No item 21 da ICPC 10 consta que a administração da entidade "pode identificar bens ou conjuntos de bens de valores relevantes ainda em operação, relevância essa medida em termos de provável geração futura de caixa, e que apresentem valor contábil substancialmente inferior ou superior ao seu valor justo em seus saldos iniciais" (CPC, 2009).

A ICPC 10 salienta ainda que "essa opção é aplicável apenas e tão somente na adoção inicial, não sendo admitida revisão da opção em períodos subsequentes ao da adoção inicial” (CPC, 2009). Portanto, não se está referindo aqui a reavaliação patrimonial, mas sim, a adoção inicial do valor justo dos ativos apenas no exercício de 2010.

Além de atribuir um valor justo aos ativos, a ICPC 10 esclarece que, na adoção inicial, "a administração deverá indicar ou assegurar que o avaliador indique a vida útil remanescente e o valor residual previsto a fim de estabelecer o valor depreciável e a nova taxa de depreciação na data de transição" (CPC, 2009).

A ICPC 10 estabelece que os ajustes decorrentes da adoção inicial do custo atribuído "sejam tratados contabilmente como ajuste direto ao patrimônio líquido, tanto positivo quanto negativo, com efeito retroativo para fins de apresentação das demonstrações contábeis comparativas" (CPC, 2009). No patrimônio líquido, a conta que registra os ajustes será Ajustes de Avaliação Patrimonial.

Quanto à realização dos valores lançados no patrimônio liquido, o ICPC 10 (CPC, 2009) expõe que "na medida em que os bens forem depreciados, amortizados ou baixados em contrapartida do resultado, os respectivos valores devem, simultaneamente, ser transferidos da conta Ajustes de Avaliação Patrimonial para a conta de Lucros ou Prejuízos Acumulados". Estabelece ainda que, em decorrência do impacto que os ajustes podem trazer ao resultado da entidade, é necessário que a administração divulgue em nota explicativa a política de dividendos que será adotada durante a realização da diferença gerada pelo novo valor. 
Os relatórios de suporte aos valores ajustados devem ser aprovados por órgão deliberativo que tenha competência formal para fazê-lo. A ICPC 10 considera como avaliadores "aqueles especialistas que tenham experiência, competência profissional, objetividade e conhecimento técnico dos bens". Esses avaliadores podem ser internos ou externos à entidade. A ICPC 10 (CPC, 2009), no seu item 34, expõe que os avaliadores precisam apresentar um relatório fundamentado, que deve conter:
a) indicação dos critérios de avaliação, das premissas e dos elementos de compa- ração adotados;
b) localização física e correlação com os registros contábeis ou razões auxiliares;
c) valor residual dos bens para as situações em que a entidade tenha o histórico e a prática de alienar os bens após um período de utilização;
d) a vida útil remanescente estimada com base em informações e alinhamento ao planejamento geral do negócio da entidade.

Neste sentido, as avaliações do deemed cost devem ser respaldadas por informações que fundamentem sua aplicação e suportem os valores reconhecidos na contabilidade.

\section{MÉTODO E PROCEDIMENTOS DA PESQUISA}

Esta pesquisa, de natureza descritiva com abordagem qualitativa, foi realizada por meio de um estudo multicaso. Para Cervo e Bervian (2002, p.66), a pesquisa descritiva "procura descobrir, com a precisão possível, a freqüência com que um fenômeno ocorre, sua relação e conexão com outros, sua natureza e características". A pesquisa caracteriza-se como descritiva por identificar e relatar como as empresas de softwares de controle patrimonial atendem às normas contábeis, emanadas pelo CPC 27 e ICPC 10.

$\mathrm{Na}$ abordagem do problema foi priorizada a pesquisa qualitativa, uma vez que visa esclarecer, analisar, compreender e descrever a complexidade do problema. Procurou-se com essa pesquisa esclarecer se os softwares patrimoniais vêm sendo adaptados às normas estabelecidas pelo CPC 27 e ICPC 10, relacionando os resultados com os preceitos descritos nestes instrumentos legais.

O estudo multicaso foi a estratégia adotada devido ao fato de proporcionar maior foco na compreensão e na comparação qualitativa dos fenômenos. O estudo multicaso proporciona maior abrangência dos resultados, não se limitando às informações de uma só organização (YIN, 2001). Adotou-se esse procedimento a fim de analisar os softwares de controle patrimonial de três empresas de softwares da região sul do Brasil. As empresas escolhidas são consideradas referências na implementação do módulo patrimonial nos sistemas Enterprise Resource Planning (ERP) nesta região.

A coleta de dados foi realizada por meio de entrevistas com o responsável pelo desenvolvimento do software em duas das empresas pesquisadas, que tiveram duração média de uma hora. Pela dificuldade de acesso ao desenvolvedor do módulo patrimonial na terceira empresa, o roteiro de entrevista foi transformado em questionário e encaminhado por e-mail ao responsável pelo módulo. Além disso, foram formulados alguns questionamentos posteriores via e-mail, no intuito de dirimir dúvidas relacionadas às respostas do questionário. 
Portanto, os sujeitos da pesquisa das entrevistas são as pessoas responsáveis pelo desenvolvimento dos módulos de controle patrimonial e da observação são consultores do módulo, questionados de acordo com a disponibilidade dos mesmos. Após a entrevista, solicitou-se a demonstração do software de controle patrimonial de cada empresa, a fim de confrontar as respostas obtidas nas entrevistas com o que de fato o sistema contempla.

O instrumento de coleta de dados utilizado na pesquisa de campo consistiu de um roteiro estruturado, elaborado com base no CPC 27 e na ICPC 10. O roteiro de entrevista foi elaborado a partir de um constructo, dividido em 10 tópicos, cada um relacionado a um aspecto descrito no CPC 27 e na ICPC 10, além de um tópico de aspectos gerais, com questões sobre a emissão de relatórios.

Antes da realização da entrevista foi aplicado um pré-teste a três profissionais da área contábil, todos professores universitários, que possuem vivência com sistemas patrimoniais. Estes profissionais sugeriram alguns ajustes no roteiro de entrevista, que foram efetuados antes da aplicação aos efetivos entrevistados.

$\mathrm{Na}$ análise dos dados, por solicitação das empresas, não foi revelada a razão social e nem mesmo evidenciados aspectos caracterizadores. Desse modo, as três empresas foram denominadas de Empresa A, Empresa B e Empresa C, mantendo-se a mesma denominação em todas as análises, a fim de promover uma análise consolidada ao final do estudo.

Na tabulação do roteiro de entrevista, dividido em 10 tópicos, com uma sequência de perguntas relacionadas a um aspecto descrito no CPC 27 e na ICPC 10, respectivamente, foram estabelecidos dois critérios para cada pergunta: atende ou não atende. O critério "atende" conferia à empresa um ponto, enquanto o critério "não atende" atribuía pontuação zero. Ao final da análise foram somados os pontos de cada tópico de modo a identificar a empresa que mais atende aos preceitos do CPC 27 e da ICPC 10.

\section{DESCRIÇÃO E ANÁLISE DOS DADOS}

Nesta seção, apresenta-se a descrição e análise dos dados coletados mediante as entrevistas aplicadas às empresas de softwares sediadas na região sul do Brasil. Os dados foram tratados sem identificação, mantendo-se a confidencialidade das empresas pesquisadas. A seguir, faz-se a análise individualizada, por tópico, conforme a sequência do constructo.

\subsection{Reconhecimento}

Inicia-se com o quadrante do software que trata do reconhecimento dos itens do Ativo Imobilizado, partindo da premissa de que o sistema contempla os campos básicos, como lançamento do custo de aquisição. O intuito das perguntas é verificar se os softwares estão preparados para receber lançamentos de todos os custos que integram um bem do ativo imobilizado, mesmo que estes custos sejam subsequentes à aquisição do bem. 
Tabela 1 - Reconhecimento dos itens do ativo imobilizado.

\begin{tabular}{|c|c|c|c|c|c|c|c|c|}
\hline \multirow{2}{*}{$\mathrm{N}^{\circ}$} & \multirow{2}{*}{ Questão } & \multirow{2}{*}{$\begin{array}{l}\text { Item } \\
\text { CPC } \\
27\end{array}$} & \multicolumn{2}{|c|}{ Empresa A } & \multicolumn{2}{|c|}{ Empresa B } & \multicolumn{2}{|c|}{ Empresa C } \\
\hline & & & 0 & 1 & 0 & 1 & 0 & 1 \\
\hline 1 & $\begin{array}{l}\text { O sistema permite inclusão posterior de sobressalentes, } \\
\text { peças de reposição, ferramentas e equipamentos que } \\
\text { venham a agregar o custo original do bem? }\end{array}$ & 8 & & $\mathrm{x}$ & & $\mathrm{X}$ & & $\mathrm{X}$ \\
\hline 2 & $\begin{array}{l}\text { O sistema permite a agregação de mais de um componente } \\
\text { a um ativo, a fim de formar o custo de um bem depreciável } \\
\text { de valor conjunto? (ex. moldes, ferramentas e bases) }\end{array}$ & 9 & & $\mathrm{x}$ & & $\mathrm{x}$ & & $\mathrm{x}$ \\
\hline 3 & $\begin{array}{l}\text { É possível incluir algum componente que aumente a vida } \\
\text { útil do bem, a um conjunto de ativos já cadastrados? }\end{array}$ & 10 & & $\mathrm{x}$ & & $\mathrm{x}$ & & $\mathrm{X}$ \\
\hline 4 & $\begin{array}{l}\text { Em caso de reposição de partes, há campo para a baixa da } \\
\text { peça que está sendo substituída e campo para a inclusão } \\
\text { da nova peça a ser imobilizada? }\end{array}$ & 13,70 & & $\mathrm{x}$ & & $\mathrm{x}$ & & $\mathrm{x}$ \\
\hline 5 & $\begin{array}{l}0 \text { sistema permite a agregação de custos com } \\
\text { manutençōes preventivas importantes ao valor do bem? }\end{array}$ & 14 & & $\mathrm{x}$ & & $\mathrm{X}$ & & $\mathrm{x}$ \\
\hline 6 & $\begin{array}{l}\text { O sistema permite o destaque dos impostos recuperáveis } \\
\text { e descontos ou abatimentos obtidos, a fim de evidenciar e } \\
\text { controlar apenas o custo líquido do item? }\end{array}$ & 16.a & & $\mathrm{x}$ & & $\mathrm{X}$ & & $\mathrm{x}$ \\
\hline 7 & $\begin{array}{l}\text { O sistema permite o agrupamento de vários itens, quando } \\
\text { da construção de um bem, e permite que o montante seja } \\
\text { depreciado apenas ao final da construção? }\end{array}$ & $\begin{array}{l}16 . b, \\
55\end{array}$ & & $\mathrm{x}$ & & $\mathrm{X}$ & & $\mathrm{x}$ \\
\hline 8 & $\begin{array}{l}\text { O sistema permite a inclusão ao valor de bem dos custos } \\
\text { com preparação do local, instalação e montagem, frete e } \\
\text { manuseio, testes, ou qualquer outro custo necessário para } \\
\text { colocar o bem em uso? }\end{array}$ & 17 & & $\mathrm{x}$ & & $\mathrm{x}$ & & $\mathrm{x}$ \\
\hline & Total do Quadrante & & & 8 & & 8 & & 8 \\
\hline
\end{tabular}

Constata-se na Tabela 1, que todos os softwares analisados atingiram 8 pontos, que é a pontuação máxima do quadrante do software. Entende-se que, por se tratar de itens que já eram contemplados pelas normas contábeis anteriores a normatização do CPC 27 , as empresas já adotavam essas funções em seus softwares.

Todos os softwares pesquisados tratam a inclusão de peças como adições ao bem original, em que a peça inclusa tem características próprias e é tratada paralelamente a este bem. Como é um item independente, pode receber vida útil específica ou ser tratado pelos critérios de vida útil do bem original, assim como pode ser baixado da respectiva conta separadamente a qualquer tempo. Os itens adicionados recebem uma sub-numeração, relacionada à numeração do item original. 
Quanto ao agrupamento de mais de um componente do ativo, todos os sistemas atendem ao critério do CPC 27. A empresa B trata esse agrupamento como uma aglutinação, em que o usuário pode selecionar quais itens devem ser agrupados. As demais empresas tratam o agrupamento como adição de vários itens a um único bem.

Também, em todos os softwares pesquisados, os gastos com serviços de manutenção que aumentem a vida útil do bem são tratados como uma adição, sendo diferenciados de uma peça substituída pela sua descrição. Da mesma forma, todos os softwares pesquisados possuem campo específico para inclusão de impostos recuperáveis que são exportados para os sistemas fiscais integrados.

Em relação às construções em andamento, os sistemas tratam as entradas de materiais e mão de obra como adições. Os itens são agrupados e transformados em um único bem, que passam a ser depreciados ao final da sua construção. Os gastos necessários para colocar o bem em uso também são tratados como adição por todas as empresas e esses valores agregam o custo do bem.

\subsection{Valor Residual}

Este quadrante contempla questões que verificam se o sistema foi adaptado ao conceito de valor residual descrito pelo CPC 27. Na Tabela 2, evidenciam-se as respostas relativas ao campo destinado à aplicação do conceito de valor residual no ativo imobilizado.

Tabela 2 - Aplicação do conceito de valor residual aos bens do ativo imobilizado.

\begin{tabular}{|c|c|c|c|c|c|c|c|c|}
\hline \multirow{2}{*}{$\mathrm{N}^{\circ}$} & \multirow{2}{*}{ Questão } & \multirow{2}{*}{$\begin{array}{c}\text { Item } \\
\text { CPC } \\
27\end{array}$} & \multicolumn{2}{|c|}{ Empresa A } & \multicolumn{2}{|c|}{ Empresa B } & \multicolumn{2}{|c|}{ Empresa C } \\
\hline & & & 0 & 1 & 0 & 1 & 0 & 1 \\
\hline 9 & Há campo para o lançamento do valor residual do bem? & 6,53 & & $\mathrm{X}$ & & $\mathrm{X}$ & & $\mathrm{X}$ \\
\hline 10 & $\begin{array}{l}0 \text { sistema permite a alteração subsequente do valor } \\
\text { residual do bem? }\end{array}$ & 6,51 & & $x$ & & $X$ & & $\mathrm{X}$ \\
\hline \multirow[t]{2}{*}{11} & $\begin{array}{l}\text { Com a alteração do valor residual de um bem não altera o } \\
\text { valor depreciável dos períodos anteriores. }\end{array}$ & 51,54 & & $X$ & & $X$ & & $\mathrm{X}$ \\
\hline & Total do Quadrante & & & 3 & & 3 & & 3 \\
\hline
\end{tabular}

Verifica-se na Tabela 2, que todas as empresas pesquisadas adequaram seus softwares ao conceito de valor residual e receberam pontuação máxima nesse quesito. Mesmo sendo uma norma estabelecida pelo CPC 27, anteriormente à sua normatização, era facultado às empresas optar pelo reconhecimento do valor residual. Desse modo, os softwares já dispunham de campos para o reconhecimento desse valor.

Todos os softwares analisados permitem que o valor residual seja alterado, desde que o usuário estabeleça o período inicial da alteração, o que impossibilita a alteração dos períodos anteriores. A empresa A ainda permite que o usuário estabeleça um valor residual em valor fixo ou um percentual sobre o custo de aquisição do bem, conforme o grupo em que o mesmo se enquadre. 


\subsection{Vida Útil}

Verifica-se neste quadrante o atendimento do software ao conceito de vida útil. Na Tabela 3 constam as respostas dos entrevistados às perguntas desse bloco, o que também pode ser confirmado na observação do pesquisador, quando da demonstração do software.

Tabela 3 - Aplicação do conceito de vida útil aos bens do ativo imobilizado.

\begin{tabular}{|c|c|c|c|c|c|c|c|c|}
\hline \multirow{2}{*}{$\mathrm{N}^{\circ}$} & \multirow{2}{*}{ Questão } & \multirow{2}{*}{$\begin{array}{c}\text { Item } \\
\text { CPC } \\
27\end{array}$} & \multicolumn{2}{|c|}{ Empresa A } & \multicolumn{2}{|c|}{ Empresa B } & \multicolumn{2}{|c|}{ Empresa C } \\
\hline & & & 0 & 1 & 0 & 1 & 0 & 1 \\
\hline 12 & $\begin{array}{l}\text { Há campo para lançamento do prazo de vida útil estimada } \\
\text { do bem? }\end{array}$ & 6,50 & & $\mathrm{x}$ & & $\mathrm{x}$ & & $\mathrm{x}$ \\
\hline 13 & $\begin{array}{l}\text { O sistema calcula a taxa de depreciação em função da vida } \\
\text { útil do bem? }\end{array}$ & 6 & & $\mathrm{x}$ & & $\mathrm{x}$ & & $\mathrm{x}$ \\
\hline 14 & O sistema permite a alteração do prazo de vida útil? & 6,51 & & $\mathrm{x}$ & & $\mathrm{x}$ & & $\mathrm{x}$ \\
\hline 15 & $\begin{array}{l}\text { A alteração da vida útil do bem não altera os períodos } \\
\text { anteriores já depreciados. }\end{array}$ & 51 & & $\mathrm{x}$ & & $\mathrm{x}$ & & $\mathrm{x}$ \\
\hline & Total do Quadrante & & & 4 & & 4 & & 4 \\
\hline
\end{tabular}

Observa-se na Tabela 3 que todas as empresas entrevistadas alcançaram 4 pontos, que corresponde a pontuação máxima neste tópico. Todos os softwares pesquisados permitem que o usuário estabeleça o prazo de vida útil dos bens. As pontuações máximas se devem ao fato de que o conceito de vida útil já era uma alternativa de uso antes da normatização do CPC 27.

Um aspecto que diferencia os softwares analisados neste quesito é a maneira de reconhecer a vida útil do bem. Na empresa $\mathrm{A}$, o usuário estabelece em meses ou anos o prazo de vida útil do bem, que pode ser alterado desde que o usuário estabeleça a data inicial da alteração. Já nas empresas B e C, o usuário precisa converter o prazo de vida útil em taxa de depreciação e lançá-la no sistema, sendo que a taxa pode ser alterada.

Neste sentido, percebe-se que, mesmo utilizando critérios diferentes, os softwares permitem reconhecer a vida útil do bem, adequando-se ao estabelecido no CPC 27.

\subsection{Depreciação}

Neste quadrante são abordadas questões referentes ao cálculo da depreciação dos bens do ativo imobilizado, assim como os métodos de depreciação que o software suporta. As respostas dos entrevistados às questões desse conjunto são apresentadas na Tabela 4. 
Tabela 4 - Cálculo e métodos de depreciação dos bens do ativo imobilizado.

\begin{tabular}{|c|c|c|c|c|c|c|c|c|}
\hline \multirow{2}{*}{$\mathrm{N}^{\circ}$} & \multirow{2}{*}{ Questão } & \multirow{2}{*}{$\begin{array}{l}\text { Item } \\
\text { CPC } \\
27\end{array}$} & \multicolumn{2}{|c|}{ Empresa A } & \multicolumn{2}{|c|}{ Empresa B } & \multicolumn{2}{|c|}{ Empresa C } \\
\hline & & & 0 & 1 & 0 & 1 & 0 & 1 \\
\hline 16 & $\begin{array}{l}\text { O sistema permite que um componente de valor } \\
\text { significativo em relação ao item do qual ele faz parte seja } \\
\text { depreciado separadamente? }\end{array}$ & 43,44 & & $\mathrm{x}$ & & $\mathrm{x}$ & & $\mathrm{x}$ \\
\hline 17 & $\begin{array}{l}\text { Caso tenham a vida útil e o método de depreciação iguais, } \\
\text { o sistema permite o agrupamento de mais de um desses } \\
\text { componentes para o cálculo de sua depreciaçăo? }\end{array}$ & 45 & & $\mathrm{X}$ & & $\mathrm{x}$ & & $\mathrm{x}$ \\
\hline 18 & $\begin{array}{l}\text { O sistema permite a parametrização da contrapartida das } \\
\text { depreciaçỗes, segregando-as em custo ou despesa? }\end{array}$ & 48,49 & & $\mathrm{X}$ & & $\mathrm{x}$ & & $\mathrm{X}$ \\
\hline 19 & $\begin{array}{l}0 \text { sistema deixa de calcular a depreciação quando o seu } \\
\text { valor contábil atingir o valor residual? }\end{array}$ & 52,54 & & $\mathrm{x}$ & & $\mathrm{x}$ & & $\mathrm{X}$ \\
\hline 20 & $\begin{array}{l}\text { O sistema permite o cálculo da depreciação pelo método } \\
\text { linear? }\end{array}$ & 62 & & $\mathrm{X}$ & & $\mathrm{x}$ & & $\mathrm{X}$ \\
\hline 21 & $\begin{array}{l}\text { O sistema permite o cálculo da depreciação pelo método } \\
\text { dos saldos decrescentes? }\end{array}$ & 62 & $\mathrm{X}$ & & $\mathrm{X}$ & & & $\mathrm{x}$ \\
\hline 22 & $\begin{array}{l}\text { O sistema permite o cálculo da depreciação pelo método } \\
\text { de unidades de produzidas? }\end{array}$ & 62 & & $\mathrm{x}$ & $\mathrm{X}$ & & & $\mathrm{x}$ \\
\hline 23 & O sistema permite a alteração do método de depreciação? & 61 & & $\mathrm{x}$ & $\mathrm{x}$ & & & $\mathrm{x}$ \\
\hline 24 & $\begin{array}{l}\text { A alteração do método de depreciação não altera os } \\
\text { períodos anteriores já depreciados. }\end{array}$ & 61 & & $\mathrm{x}$ & & $\mathrm{x}$ & & $\mathrm{x}$ \\
\hline \multirow[t]{2}{*}{25} & $\begin{array}{l}0 \text { sistema permite cessar o processo de depreciação de um } \\
\text { bem, quando este é classificado como mantido para venda? }\end{array}$ & 55 & & $\mathrm{X}$ & & $\mathrm{x}$ & & $\mathrm{x}$ \\
\hline & Total do Quadrante & & 0 & 9 & 0 & 7 & 0 & 10 \\
\hline
\end{tabular}

Verifica-se na Tabela 4, que há diferenças no software das três empresas analisadas. O destaque foi para a empresa $\mathrm{C}$, que apresentou a pontuação máxima do quadrante, contemplando os 10 pontos possíveis. Na sequência, tem-se a empresa $\mathrm{A}$, com 9 pontos, que não alcançou a pontuação máxima por não atender ao item 21 , relacionado ao método de depreciação dos saldos decrescentes. A empresa B apresenta a menor pontuação, 7 pontos, por não ter contemplado os itens 21,22 e 23. O software dessa empresa atende apenas a um método de depreciação e não há possibilidade de alteração desse método.

Os quesitos que menos pontuaram estão relacionados aos métodos de depreciação, uma vez que apenas a Empresa $\mathrm{C}$ atende a todos os métodos. A Empresa A trabalha apenas com o método linear e unidades produzidas, que são estabelecidos de acordo com a escolha da unidade de medida, ou seja, quando a unidade for tempo o cálculo será linear, quando o critério for unidades de produção será utilizado o método de unidades produzidas. Já a Empresa B, atende apenas ao método linear.

Nos demais quesitos, que estão relacionados à separação ou agregação de itens e cessão da depreciação, todas as empresas pesquisadas alcançaram a pontuação máxima. 


\subsection{Impairment}

Buscou-se ainda verificar nos softwares os aspectos relacionados ao reconhecimento do impairment. As respostas às perguntas desse quadrante constam na Tabela 5.

Tabela 5 - Reconhecimento do impairment nos itens do ativo imobilizado.

\begin{tabular}{|c|c|c|c|c|c|c|c|c|}
\hline \multirow{2}{*}{$\mathrm{N}^{\circ}$} & \multirow{2}{*}{ Questão } & \multirow{2}{*}{$\begin{array}{c}\text { Item } \\
\text { CPC } \\
27\end{array}$} & \multicolumn{2}{|c|}{ Empresa A } & \multicolumn{2}{|c|}{ Empresa B } & \multicolumn{2}{|c|}{ Empresa C } \\
\hline & & & 0 & 1 & 0 & 1 & 0 & 1 \\
\hline 26 & $\begin{array}{l}\text { Há campo para o reconhecimento do valor do bem após } \\
\text { o cálculo do impairment? }\end{array}$ & 63 & $\mathrm{X}$ & & $X$ & & $X$ & \\
\hline & Total do Quadrante & & 0 & & 0 & & 0 & \\
\hline
\end{tabular}

Conforme apresentado na Tabela 5, os softwares das empresas não contemplam os aspectos relacionados ao impairment, as três empresas não pontuaram. $\mathrm{O}$ não atendimento a este quesito pode decorrer do fato de que o CPC 27 não estabelece critérios para o cálculo do impairment, apenas menciona que o teste deve ser aplicado a todos os ativos imobilizados conforme os critérios do CPC 01. Neste sentido, entende-se que não é função do sistema patrimonial calculá-lo, mas apenas reconhecer a desvalorização dos ativos imobilizados de acordo com o teste aplicado.

Além disso, percebeu-se nas entrevistas que os respondentes das empresas objeto de estudo desconhecem o conceito de impairment. Os entrevistados informaram que nenhum cliente havia solicitado alguma implantação neste sentido.

\subsection{Adoção Inicial dos preceitos do CPC 27}

As questões da Tabela 6 referem-se à adequação dos sistemas patrimoniais em relação ao reconhecimento e controle dos ajustes da adoção inicial do CPC 27, conforme estabelecido pela ICPC 10.

Tabela 6 - Reconhecimento e controle dos ajustes da adoção inicial do CPC 27 conforme a ICPC 10.

\begin{tabular}{|c|c|c|c|c|c|c|c|c|}
\hline \multirow{2}{*}{$\mathrm{N}^{\circ}$} & \multirow{2}{*}{ Questão } & \multirow{2}{*}{$\begin{array}{l}\text { Item } \\
\text { CPC } \\
27\end{array}$} & \multicolumn{2}{|c|}{ Empresa A } & \multicolumn{2}{|c|}{ Empresa B } & \multicolumn{2}{|c|}{ Empresa C } \\
\hline & & & 0 & 1 & 0 & 1 & 0 & 1 \\
\hline 35 & $\begin{array}{l}\text { É possível reconhecer o valor do ajuste ao custo } \\
\text { atribuído (deemed cost) ao item do ativo imobilizado? }\end{array}$ & $\begin{array}{l}\text { ICPC10- } \\
\text { Item } 8\end{array}$ & $X$ & & $X$ & & $X$ & \\
\hline 36 & $\begin{array}{l}\text { O sistema permite a adequação da vida útil do bem, } \\
\text { quando do ajuste destes saldos? }\end{array}$ & $\begin{array}{l}\text { ICPC10- } \\
\text { Item } 23\end{array}$ & $X$ & & $X$ & & $X$ & \\
\hline 37 & $\begin{array}{l}0 \text { sistema permite a adequação do valor residual do } \\
\text { bem, quando do ajuste destes saldos? }\end{array}$ & $\begin{array}{l}\text { ICPC10- } \\
\text { Item } 23\end{array}$ & $X$ & & $X$ & & $X$ & \\
\hline \multirow[t]{2}{*}{38} & $\begin{array}{l}\text { O sistema permite o controle da realização do ajuste } \\
\text { efetuado no Patrimônio Líquido - Ajustes de Avaliação } \\
\text { Patrimonial? }\end{array}$ & $\begin{array}{l}\text { ICPC10- } \\
\text { Item } 26\end{array}$ & $X$ & & $X$ & & $X$ & \\
\hline & Total do Quadrante & & 0 & & 0 & & 0 & \\
\hline
\end{tabular}


Nota-se na Tabela 6, que nenhuma das empresas entrevistadas pontuou neste tópico. Observou-se nas entrevistas que os respondentes desconhecem o conceito de deemed cost.

A ICPC 10 prevê que, conforme estabelecido pelo OCPC 02, em 2010 devem ser reconhecidos os ajustes referente à Adoção Inicial do CPC 27. Estes ajustes devem ser reconhecidos na contabilidade e, consequentemente, precisam ser controlados por meio do sistema patrimonial.

Todos os entrevistados alegaram desconhecer a necessidade do ajuste por adoção inicial no exercício 2010. Sugeriram, no entanto, que seria possível como alternativa fazer o reconhecimento dos ajustes de adoção inicial usando as mesmas funções do reconhecimento das reavaliações dos softwares. Porém, consideraram mais interessante a criação de um campo específico para o reconhecimento e controle desses ajustes.

\subsection{Resultado consolidado das respostas dos entrevistados}

Nesta seção demonstram-se os resultados dos 10 quadrantes de forma consolidada, com o intuito de verificar qual software mais atende às exigências do CPC 27 e da ICPC 10.

Tabela 7 - Resultado consolidado das respostas dos entrevistados.

\begin{tabular}{|c|c|c|c|c|c|c|c|c|}
\hline \multirow{2}{*}{$\mathrm{N}^{\circ}$} & \multirow{2}{*}{ Quadrante } & \multirow{2}{*}{$\begin{array}{l}\text { Total de } \\
\text { Questões }\end{array}$} & \multicolumn{2}{|c|}{ Empresa A } & \multicolumn{2}{|c|}{ Empresa B } & \multicolumn{2}{|c|}{ Empresa C } \\
\hline & & & $\begin{array}{c}\mathrm{N}^{\circ} \text { de } \\
\text { Questões }\end{array}$ & $\%$ & $\begin{array}{c}\mathrm{N}^{\circ} \text { de } \\
\text { Questões }\end{array}$ & $\%$ & $\begin{array}{c}\mathrm{N}^{\circ} \mathrm{de} \\
\text { Questões }\end{array}$ & $\%$ \\
\hline 1 & Reconhecimento & 8 & 8 & $100 \%$ & 8 & $100 \%$ & 8 & $100 \%$ \\
\hline 2 & Valor Residual & 3 & 3 & $100 \%$ & 3 & $100 \%$ & 3 & $100 \%$ \\
\hline 3 & Vida Útil & 4 & 4 & $100 \%$ & 4 & $100 \%$ & 4 & $100 \%$ \\
\hline 4 & Depreciação & 10 & 9 & $90 \%$ & 7 & $70 \%$ & 10 & $100 \%$ \\
\hline 5 & Impairment & 1 & 0 & - & 0 & - & 0 & - \\
\hline 6 & Baixas & 2 & 2 & $100 \%$ & 2 & $100 \%$ & 2 & $100 \%$ \\
\hline 7 & Reavaliação & 3 & 3 & $100 \%$ & 3 & $100 \%$ & 3 & $100 \%$ \\
\hline 8 & Aspecto Contábil x Fiscal & 3 & 3 & $100 \%$ & 3 & $100 \%$ & 3 & $100 \%$ \\
\hline 9 & Adoção Inicial & 4 & 0 & - & 0 & - & 0 & - \\
\hline \multirow[t]{2}{*}{10} & Aspectos Gerais & 6 & 6 & $100 \%$ & 6 & $100 \%$ & 6 & $100 \%$ \\
\hline & Total dos Quadrantes & 44 & 38 & $86 \%$ & 36 & $82 \%$ & 39 & $89 \%$ \\
\hline
\end{tabular}

Conforme demonstrado na Tabela 7, a que mais atendeu aos critérios descritos pelo CPC 27 foi a Empresa C, com 39 pontos, que corresponde ao atendimento de $89 \%$ do total de questões. Em seguida tem-se a Empresa A, que alcançou 38 pontos, correspondendo a $86 \%$ do total. Nota-se que esta Empresa A ficou atrás da primeira colocada em decorrência do tópico depreciação, uma vez que não atendeu um dos métodos de depreciação descritos pelo CPC 27. A Empresa B, com a menor pontuação, alcançou 36 pontos das 44 possíveis, que equivale a $82 \%$ do total de questões. Sua diferença em relação às demais ocorreu pelo não atendimento aos métodos de depreciação. 
Portanto, o quadrante 4, que trata da depreciação, foi o que apresentou maior divergência entre as empresas entrevistadas. Por outro lado, o quadrante 5, impairment, e o quadrante 9, adoção inicial, obtiveram pontuação zero. Entende-se que isso é consequência do fato de se tratar de conceitos normatizados recentemente pelo CPC 01 e ICPC 10 e que têm obrigatoriedade de aplicação estabelecida para o exercício 2010. Assim, os profissionais desenvolvedores de sistemas de informação necessitam se aprofundar com urgência no assunto, dada a necessidade de sua aplicação pelas empresas.

Quanto aos demais quadrantes, é possível perceber que os quesitos relacionados a conceitos já existentes, como é o caso dos quadrantes 6,7 e 8, ou que não apresentaram significativas alterações com a normatização do CPC 27, todos obtiveram pontuação máxima das empresas. De modo geral, é possível considerar que o atendimento aos quesitos do CPC 27 e da ICPC 10 é satisfatório, já que as três empresas entrevistadas apontaram que a adequação aos quadrantes analisados oscila entre o mínimo de $82 \%$ e o máximo de $89 \%$.

\section{CONCLUSÕES}

A convergência da contabilidade às normas internacionais trouxe a necessidade de estudo $\mathrm{e}$ atualização por parte dos profissionais de contabilidade. Todavia, esses profissionais, além de conhecer as novas regras, precisam ter à sua disposição instrumentos que os auxiliem na execução de suas tarefas diárias. Neste sentido, objetivou-se neste estudo verificar se os softwares patrimoniais atendem aos preceitos do CPC 27 e da ICPC 11.

Apesar dos métodos de reconhecimento dos ativos imobilizados não terem sido alterados, o CPC 27 incluiu alguns conceitos e tornou obrigatórios alguns procedimentos. Como principais mudanças advindas com o CPC 27 citam-se: a obrigação de reconhecer um valor residual ao custo do ativo, a fim de estabelecer o valor depreciável do bem; e depreciá-lo pelo seu prazo de vida útil. Essa depreciação deve ser reconhecida no resultado por um dos três métodos estabelecidos no CPC 27, sendo eles, o método linear, decrescente ou pelas unidades produzidas. Além disso, tornou obrigatório o impairment para os ativos em uso, que, mesmo sendo estabelecido pelo CPC 01, afeta diretamente o valor dos ativos imobilizados.

Por sua vez, a principal mudança inserida pela ICPC 10 foi a aplicação do deemed cost, que prevê o ajuste dos ativos imobilizados ao seu valor justo no exercício de 2010, além de determinar a vida útil e o valor residual desses ativos.

Constatou-se na pesquisa realizada por meio de um estudo multicaso, que a empresa com maior atendimento aos critérios do CPC 27 e da ICPC 10 atendeu $89 \%$ das questões aplicadas, o que permite dizer que o nível de aplicabilidade do CPC é satisfatório nos softwares analisados. O mesmo ocorre com as demais empresas que atenderam $86 \%$ e $82 \%$ dos tópicos verificados, respectivamente.

O controle paralelo da depreciação fiscal e contábil também foi atendido por todos os sistemas pesquisados, pois já estavam preparados para atender duas formas de depreciação, devido ao controle gerencial e fiscal utilizados pelos usuários. Já os aspectos gerais, relacionados aos relatórios gerados pelos sistemas, estão sendo $100 \%$ atendidos, uma vez que todas as empresas oferecem flexibilidade na formatação dos relatórios.

Portanto, em resposta à pergunta da pesquisa conclui-se que, de modo geral, os preceitos do CPC 27 e da ICPC 10 são contemplados nos softwares de controle patrimonial analisados, já que a média geral das três empresas pesquisadas foi de $86 \%$ de atendimento aos critérios estabelecidos. A exceção constatada foi na aplicação dos conceitos de impairment e adoção inicial (deemed cost).

Consideradas as limitações dessa pesquisa, apresentam-se recomendações para futuros estudos relativos a consonância da aplicação do CPC 27 e da ICPC 10 nos softwares de controle patrimonial. Assim, recomenda-se ampliar o número de empresas para avaliação dos softwares patrimoniais, considerando o espectro em nível nacional. Outra sugestão é realizar pesquisas sobre a aplicação do deemed cost em softwares de controle patrimonial. 


\section{REFERÊNCIAS}

BANCO CENTRAL DO BRASIL (BACEN). Comunicação BACEN no 14.259, de 10 de março de 2006. Comunica procedimentos para a convergência das normas de contabilidade e auditoria aplicáveis às instituições financeiras e às demais instituições autorizadas a funcionar pelo Banco Central do Brasil com as normas internacionais promulgadas pelo International Accounting Standards Board (IASB) e pela International Federation of Accountants (IFAC). Disponível em: $<$ http:// www.fiscosoft.com.br/g/32fe/comunicado-banco-central-do-brasil-bacen-n-14259-de-10032006> . Acesso em: 13 jun. 2010.

BAUM, A.; DEVANEY, S. Depreciation, income distribution and the UK Reit. Journal of Property Investment \& Finance. v. 26, n. 3, p. 195-209, 2008.

BRASIL. Lei n ${ }^{\circ}$ 6.404, de 15 de dezembro de 1976. Dispõe sobre as sociedades por ações. Disponível em: <http://www.planalto.gov.br/ccivil_03/Leis/L6404consol.htm>. Acesso em: 03 mar. 2010.

BRASIL. Lei $\mathbf{n}^{\circ}$ 11.638, de 28 de dezembro de 2007. Altera e revoga dispositivos da Lei no 6.404, de 15 de dezembro de 1976, e da Lei no 6.385, de 7 de dezembro de 1976, e estende às sociedades de grande porte disposições relativas à elaboração e divulgação de demonstrações financeiras Disponível em:<www.planalto.gov.br/ccivil_03/_Ato2007-2010/2007/Lei/L11638.htm>. Acesso em: 03 mar. 2010.

CARVALHO; R. M. F.; LIMA, D. V.; FERREIRA, L. O. G. Processo de reconhecimento e mensuração do ativo imobilizado no setor público face aos padrões contábeis internacionais: um estudo de caso na ANATEL. Revista Universo Contábil, v. 8, n. 3, p. 62-81, 2012.

CERVO, A. L.; BERVIAN, P. A. Metodologia científica. 5. ed. São Paulo: Prentice Hall, 2002.

COMISSÃO DE VALORES MOBILIÁRIOS (CVM). Deliberação da CVM nº 583/09, de 03 de agosto de 2009. Aprova o Pronunciamento Técnico CPC 27 do Comitê de Pronunciamentos Contábeis, que trata de ativo imobilizado. Disponível em: < http://www.cvm.gov.br/port/snc/deli583. pdf >. Acesso em: 13 jun. 2010.

COMISSÃO DE VALORES MOBILIÁRIOS (CVM). Deliberação da CVM nº 619/09, de 22 de dezembro de 2009. Aprova a Interpretação Técnica ICPC 10 do Comitê de Pronunciamentos Contábeis, que trata da aplicação inicial ao ativo imobilizado e à propriedade para investimento dos Pronunciamentos Técnicos CPC 27, 28, 37 e 43. Disponível em: < http://www.cvm.gov.br/port/snc/ deli619.doc $>$. Acesso em: 13 jun. 2010.

COMITÊ DE PRONUNCIAMENTOS CONTÁBEIS (CPC). CPC 01 - Redução ao valor recuperável de ativos, de 17 de setembro de 2007. Disponível em: <http://www.cpc.org.br/mostraOrientacao.php?id=37>. Acesso em: 20 fev. 2010.

COMITÊ DE PRONUNCIAMENTOS CONTÁBEIS (CPC). CPC 20 - Custos de empréstimos, de 20 de outubro de 2011. Disponível em: $<$ http://static.cpc.mediagroup.com.br/Documentos/281_ CPC20_R1.pdf>. Acesso em: 26 jun. 2014.

COMITÊ DE PRONUNCIAMENTOS CONTÁBEIS (CPC). CPC 27 - Ativo imobilizado, de 31 de julho de 2009. Disponível em: <http://static.cpc.mediagroup.com.br/Documentos/316_CPC_27_ rev\%2003.pdf >. Acesso em: 20 fev. 2010.

COMITÊ DE PRONUNCIAMENTOS CONTÁBEIS (CPC). CPC 37 - Adoção inicial das normas internacionais de contabilidade, de 02 de dezembro de 2010. Disponível em: <http://static.cpc. mediagroup.com.br/Documentos/402_CPC_37_R1_rev\%2004.pdf $>$. Acesso em: 26 jun. 2014.

COMITÊ DE PRONUNCIAMENTOS CONTÁBEIS (CPC). CPC 43 - Aplicação inicial dos pronunciamentos técnicos CPCs 14 a 41, de 16 de dezembro de 2010. Disponível em: <http://static. cpc.mediagroup.com.br/Documentos/426_CPC43_R1.pdf>. Acesso em: 26 jun. 2014. 
COMITÊ DE PRONUNCIAMENTOS CONTÁBEIS (CPC). ICPC 10 - Interpretação sobre a aplicação inicial ao ativo imobilizado e à propriedade para investimento dos Pronunciamentos Técnicos CPCs 27, 28, 37 e 43, de 24 de dezembro de 2009. Disponível em: <http://static.cpc.mediagroup.com.br/Documentos/102_ICPC_10.pdf >. Acesso em: 20 fev. 2010.

CONSELHO FEDERAL DE CONTABILIDADE (CFC). Resolução $\mathbf{n}^{\circ}$. 1.177, de 04 de agosto de 2009. Aprova a NBC TG 27 - Ativo Imobilizado. Disponível em: <http://www.normaslegais.com. br/legislacao/resolucaocfc1177_2009.htm>. Acesso em: 11 abr. 2010.

CONSELHO FEDERAL DE CONTABILIDADE (CFC). Resolução no ${ }^{\circ} \mathbf{1 . 2 6 3}$, de 10 de dezembro de 2009. Aprova a ITG 10 - Interpretação sobre a Aplicação Inicial ao Ativo Imobilizado e à Propriedade para Investimento. Disponível em: <http://www.cfc.org.br/sisweb/sre/docs/RES_1263.doc $>$. Acesso em: 11 abr. 2010.

FINANCIAL ACCOUNTING STANDARDS BOARD (FASB). SFAS 142 - Goodwill and other intangible assets. 2001a. Disponível em: $<$ http://www.fasb.org/pdf/fas142.pdf $>$. Acesso em: 26 jun. 2014.

FINANCIAL ACCOUNTING STANDARDS BOARD (FASB). SFAS 144 - Accounting for the impairment or disposal of long-lived assets. 2001b. Disponível em: $<$ http://www.fasb.org/summary/ stsum144.shtml>. Acesso em: 26 jun. 2014.

IASPLUS. IAS 16 - Property, plant and equipment. Dec. 2003. Disponível em: <http://www.iasplus.com/standard/ias16.htm>. Acesso em: 13 jun. 2010.

INTERNATIONAL ACCOUNTING STANDARDS BOARD (IASB). IAS 36 - Impairment of assets. March, 2004. Disponível em: $<$ http://www.iasplus.com/en/standards/ias/ias36 $>$. Acesso em: 26 jun. 2014.

IUDÍCIBUS, S. Teoria da contabilidade. 7. ed. São Paulo: Atlas, 2004.

IUDÍCIBUS, S.; MARTINS, E.; GELBCKE, E. R. Manual de contabilidade das sociedades por ações: aplicável às demais sociedades. 7. ed. São Paulo: Atlas, 2007.

MACEDO, M. A. S.; MACHADO, M. A. V.; MACHADO, M. R. Análise da relevância da informação contábil no Brasil num contexto de convergência às normas internacionais de contabilidade. Revista Universo Contábil, v. 9, n. 1, p. 65-85, jan./mar., 2013.

MARTINS, O. S.; PAULO, E. O reflexo da adoção das ifrs na análise de desempenho das companhias de capitalaberto no Brasil. Revista de Contabilidade e Organizações, v. 4, n. 9, p. 31-54, 2010.

RAUPP, F. M.; BEUREN, I. M. Contribuição ao processo de mensuração de ativos imobilizados por meio do fair value e do impairment test. Revista de Informação Contábil, v. 3, n. 2, p. 1-16, 2009.

REINSTEIN, A.; LANDER, G. H. Implementing the impairment of assets requirements os SFAS no 144: an empirical analysis. Managerial Auditing Journal. v. 19, n. 3, p. 400-411, 2004.

SANTOS, J. L.; SCHMIDT, P. Contabilidade societária: atualizado pela Lei n ${ }^{\circ}$ 10.303/01. São Paulo: Atlas, 2002.

SILVA, P. D. A.; MARQUES, J. A. V. C.; SANTOS, O. M. Análise da evidenciação das informações sobre o impairment dos ativos de longa duração de empresas petrolíferas. BASE. Revista de Administração e Contabilidade da Unisinos, v. 6, n. 3, p. 258-274, 2009.

SOUZA, M. M.; BORBA, J. A.; ZANDONAI, F. Evidenciação da perda no valor recuperável de ativos nas demonstrações contábeis: uma verificação nas empresas de capital aberto brasileiras. Contabilidade Vista \& Revista, v. 22, n. 2, p. 67-91, 2011.

YIN, R. K. Estudo de caso: planejamento e métodos. 3. ed. Porto Alegre: Bookman, 2001. 
